BULLETIN Bulletin hispanique

HISPANIQUE Université Michel de Montaigne Bordeaux

122-1 | 2020

Variations donjuanesques

\title{
Cervantes transatlántico / Transatlantic Cervantes
}

New York, Peter Lang, colección Ibérica, Vol. 48, 2019

Jean-Michel Wissmer

\section{(2) OpenEdition}

Journals

Edición electrónica

URL: http://journals.openedition.org/bulletinhispanique/10987

DOI: 10.4000/bulletinhispanique.10987

ISSN: 1775-3821

Editor

Presses universitaires de Bordeaux

Edición impresa

Fecha de publicación: 18 junio 2020

Paginación: 348-351

ISBN: 979-10-300-0592-9

ISSN: 0007-4640

Referencia electrónica

Jean-Michel Wissmer, «Cervantes transatlántico / Transatlantic Cervantes», Bulletin hispanique [En línea], 122-1 | 2020, Publicado el 18 junio 2020, consultado el 19 enero 2021. URL: http://

journals.openedition.org/bulletinhispanique/10987 ; DOI: https://doi.org/10.4000/bulletinhispanique. 10987

Este documento fue generado automáticamente el 19 enero 2021.

Tous droits réservés 


\section{Cervantes transatlántico / Transatlantic Cervantes}

New York, Peter Lang, colección Ibérica, Vol. 48, 2019

Jean-Michel Wissmer

\section{REFERENCIA}

Cervantes transatlántico / Transatlantic Cervantes, Editado por Francisco RAMíREZ SANTACRUZ y Pedro Ángel Palou. - New York: Peter Lang, colección Ibérica, Vol. 48, 2019, 168 p. ISBN-10: 1433164434 - ISBN-13: 978-1433164439.

1 En su introducción, los editores de este volumen bilingüe (español/inglés), Francisco Ramírez Santacruz y Pedro Ángel Palou, confiesan que el tema de la relación de Cervantes con América «es harto conocido». Sin embargo, la perspectiva multidisciplinaria no deja de ser novedosa, ya que nos lleva del Siglo de Oro hasta nuestros días tocando aspectos tan diversos como la interpretación de la obra cervantina y su recepción en América, las figuras de los indianos y de los indios, o incluso la versión animada del Quijote. Con la imposibilidad de resumir de manera completa todos los ensayos incluidos en este libro, me concentraré en los que más se acercan al tema puramente literario.

Los especialistas invitados no se limitan al hidalgo de la Mancha ni mucho menos. Ignacio García Aguilar recuerda que, en su Canto de Calíope, Cervantes propone un catálogo de ingenios literarios que incluye a quince escritores novohispanos, tanto los que nacieron en América como los que desarrollaron en un momento dado su actividad literaria en el Nuevo Mundo. Otro catálogo es el del donoso escrutinio del cura y del barbero en la primera parte del Quijote (I, 6), mucho más amplio, ya que «se recopilan autores tanto del hoy como del ayer» (p.7) y en el que se mencionan a poetas novohispanos como Alonso de Ercilla - el cura considera su Araucana como una joya de poesía -y Bernardo de la Vega, quien aparecerá también pero de forma negativa- a causa de rencores personales por parte del alcalaíno -en el Viaje del Parnaso. Isabel 
Lozano-Renieblas completa este análisis y argumenta que este interés por lo americano y su deseo de pasar a las Indias le vienen probablemente de su proximidad con indianos y de sus contactos con miembros de la familia Corzo durante su cautiverio en Argel. Como es bien sabido, intentó sin éxito dos veces (en 1582 y 1590) conseguir un puesto en el Nuevo Mundo. Es famosa la sentencia del Consejo de Indias que dice : «busque por acá en que se le haga merced». No se comenta acerca de la posibilidad de que este rechazo tuviera como motivo la ascendencia judía del autor. La profesora subraya los frecuentes «préstamos de origen americano» (p. 69) y demuestra cómo los bárbaros del Persiles están «rodeados de un entorno más propio de los indios americanos que de los pueblos septentrionales» (p. 70). Tienen costumbres parecidas y practican sacrificios humanos. De la misma manera, Cory A. Reed afirma la estrecha conexión entre la epopeya de Ercilla y La Numancia de Cervantes : «The Numantinos share similarities with the "nobles savages" of Araucana, including their pagan religious rituals» (p. 106). Según Reed, esta comparación podría interpretarse como una forma lascasiana de empatía por los sufrimientos de los pueblos conquistados.

3 Francisco Ramírez Santacruz resume de forma cristalina lo que fue la recepción y el éxito de la obra cervantina en la Nueva España, y eso a pesar de la prohibición -en realidad nada eficaz- de introducir obras de ficción. Al revés, indica que «ningún poeta novohispano del siglo XVII lo mencione [a Cervantes] o aluda a sus personajes» (p. 88) con la notable excepción de sor Juana Inés de la Cruz que hace en dos poemas y en Los empeños de una casa alusiones específicas al Quijote. «Con todo, que la jerónima haya sido entre todos sus contemporáneos novohispanos quien más referencias haya hecho al creador de la novela moderna la distingue una vez más de todos ellos» (p. 88). Se trata de los episodios de Clavileño, Melisendra y maese Pedro. En su respuesta a un caballero anónimo que compara a la monja-poeta con el Fénix, sor Juana juega el juego empezando a creer que ella es efectivamente ese Fénix. «... [i] he de echar yo / aqueste honor en la calle ?», se pregunta maliciosamente sor Juana. El investigador propone a partir de ahí toda una reflexión muy sofisticada demostrando -por primera vez- cómo la mexicana y el alcalaíno comparten la misma fascinación por el tema de la identificación con entes de ficción. En el Quijote la figura del galeote Ginés de Pasamonte se convierte en la del escritor y así se afirma nuevamente esta identificación/confusión entre ficción y realidad. Estos ejemplos «muestran un ser desdoblado [sor Juana] que se reconoce más con la Fénix que con la monja» (p. 100), comenta Ramírez Santacruz. En muchos sentidos, concluye, la jerónima se adelanta a una visión borgesiana; añadiría que, lamentablemente, Borges probablemente nunca leyó a sor Juana.

4 No es de extrañarse que el autor argentino con su «Pierre Ménard, autor del Quijote» sea el tema de dos artículos de esta publicación. Michael Scham recuerda el doble legado europeo y criollo de Borges: «the paternal legacy of the library, heavily populated by books of the Anglo tradition; the maternal lineage of warriors and conquistadores» (p. 135). Paradoja suprema o perfecto ejemplo de este doble linaje familial, cultural e intelectual (que también incluye los países nórdicos), no se hace mención del hecho de que Borges leyó por primera vez Don Quijote ... jen inglés! Lo nórdico y lo argentino terminan por reunirse -para decirlo así- en la fascinación de Borges por los bárbaros del norte y los cuchilleros de Buenos Aires: «El otro, el mismo ranges from Nordic sagas to Barrio Norte and other Buenos Aires neighborhoods, from daggers in desk drawers to armies pitched in epic battle on the plains» (p.139). Otra vez, se trata de la transformación y/o negación de la realidad, ya que el narrador de «Juan Muraña» (Borges...) nunca conoció realmente el 
universo de los cuchilleros: "Palermo del cuchillo y de la guitarra andaba (me aseguran) por las esquinas» (p. 142). «Me aseguran»... En la realidad, un muro concreto y simbólico -o mejor dicho una reja- separaba la casa de Borges del mundo de los cuchilleros y compadritos. En este sentido, el escritor argentino se asemeja al caballero andante soñando su vida. Jutta Weiser resume la complicada e intrincada composición del Quijote (el original...) con todos sus niveles de lectura y escritura. Aunque bien conocida, la confusión entre el autor verdadero (Cervantes), el cronista ficticio-original (Cide Hamete Benengeli), el traductor «poco fiable», y el imitador-falsificador pero sí de carne y hueso (Avellaneda), todos reunidos por un narrador principal, no deja de ser fascinante. Tanto en Magias parciales como en Pierre Ménard, «Borges se interesó particularmente por los diferentes niveles diegéticos, tan importantes en las cuestiones de autoría y lectura» (p. 151). «Los entes ficticios se convierten en lectores» (p. 152), como Pierre Ménard, a la vez autor y lector, quien copia a su modelo para hacerlo «más rico», dice Borges.

5 Pedro Ángel Palou tiene la difícil tarea de describir y analizar una obra tan compleja como Terra Nostra de Carlos Fuentes, obra que Palou define como un «monumento novelístico», una «mirada americana de la locura hispánica o capítulo americano del infinito libro del Ingenioso Hidalgo» (p. 84). Y de ahí la referencia a Cervantes, ya que don Quijote aparece en la novela al lado de la(s) Celestina(s) (puesto que son tres...) y de Don Juan, siendo este último don Quijote en su juventud. El héroe de Cervantes tiene un papel central, el de «contradecir la función del realismo en la modernidad capitalista y criticar la inequidad a través de la ambigüedad, el pluralismo» (p. 83).

6 Me parece que son esos artículos los que más se complementan y permiten entablar este diálogo literario transatlántico. La perspectiva de Adrián J. Sáez es más histórica, ya que está centrada en la figura de Hernán Cortés. Cortés representa el «héroe maltratado» que no recibió los honores esperados después de su conquista de México, y Cervantes hubiera podido proyectarse perfectamente en la figura del conquistador después de su cautiverio en Argel y de sus peticiones frustradas para obtener un puesto en el Nuevo Mundo. Sin embargo, parece que la comparación se queda por ahí, ya que la autoría de los dos poemas de Cervantes dedicados a Cortés es bastante dudosa. Francisco Layna Ranz introduce aspectos históricos y antropológicos con su artículo sobre Matilde de la Torre : «... cuando [España] halló de pronto en la inmensidad americana una riqueza de fantasía, perdió el norte del derecho europeo para entrar en el ensueño del imperialismo conquistador «(p. 19). Sería el «error americano», según la escritora española. Obed Lira ofrece una visión política de Cervantes, quien en su novela ejemplar Rinconete y Cortadillo introduce «ethical questions regarding Spanish colonization» (p. 33) influidas por los textos de Bartolomé de las Casas.

7 Para ser completo hay que mencionar el artículo de Álvaro Llosa Sanz, cuyo tema, la serie de animación de Ubbe Eert Iwerks, se aparta de los demás estudios. Esta serie pertenece a una larga lista de adaptaciones, «generalmente muy libres, cultural e ideológicamente reapropriadas» (p. 49), tanto heredadas como contemporáneas. Daré dos ejemplos: el hecho de que don Quijote encarcelado esté vigilado por un sheriff, o cuando ataca un dragón que en realidad es una grúa excavadora. Comenta Álvaro Llosa Sanz : «Don Quijote se representa como un héroe a través de los tiempos, desconfiado o abrumado ante la idea de progreso tecnológico, que se enfrenta al paradigma del materialismo tecnológico visto como un fantasma al que temer como a un gigante o a un dragón» (p. 60). 
8 Así, el lector confrontado felizmente con este ambicioso proyecto, descubrirá nuevos territorios cervantinos. Tal vez se quede con el deseo de continuar el viaje, ya que la obra de Cervantes no es solamente transatlántica sino más bien universal. Pero eso sería el tema de muchos otros volúmenes.

\section{AUTORES}

JEAN-MICHEL WISSMER

Genève - Suisse 